Christof Forderer • Ich-Eklipsen 


\section{Christof Forderer}

\section{Ich-Eklipsen}

Doppelgänger in der Literatur seit 1800

Verlag J. B. Metzler Stuttgart - Weimar 
Die Deutsche Bibliothek - CIP-Einheitsaufnahme

Forderer, Christof:

Ich-Eklipsen : Doppelgänger in der Literatur seit 1800 / Christof Forderer. Stuttgart ; Weimar : Metzler, 1999

(M-und-P-Schriftenreihe für Wissenschaft und Forschung)

ISBN 978-3-476-45209-2

\author{
ISBN 978-3-476-45209-2 \\ ISBN 978-3-476-04303-0 (eBook) \\ DOI 10.1007/978-3-476-04303-0
}

Dieses Werk ist einschließlich aller seiner Teile geschützt. Jede Verwertung außerhalb der engen Grenzen des Urheberrechtsgesetzes ist ohne Zustimmung des Verlages unzulässig und strafbar. Das gilt insbesondere für die Vervielfältigungen, Übersetzung, Mikroverfilmungen und Einspeicherung in elektronischen Systemen.

M \& P Schriftenreihe für Wissenschaft und Forschung

(C) 1999 Springer-Verlag GmbH Deutschland

Ursprünglich erschienen bei J.B. Metzlersche Verlagsbuchhandlung und Carl Ernst Poeschel Verlag GmbH in Stuttgart 1999 
Pascale, der einzigen 


\section{Inhalt}

EINLEITUNG

1. DOPPELGÄNGER UND ICHPROBLEMATIK UM 1800

Identitätsturbulenz als $\mathrm{Spa}$ in Doppelgängertexten der Plautus-Tradition - PlautusStoffe mit neuen Inhalten: Hoffmanns "Doppeltgänger", Kleists "Amphitryon" • Fragilität des neuzeitlichen Ich, Doppelgängerthematik und das sich überfordernde Ich bei Herder

2. DAS ABSOLUTE ICH ALS DOPPELGÄNGER

Jean Pauls Auseinandersetzung mit dem Subjektivismus • Idealistische Philosophie und Doppelgängerparanoia im "Titan"

3. ENTGLEITENDE IDENTITÄT

Identitätsdiffusion in Hoffmanns "Elixieren des Teufels" - Sorge um Identität und romantische Beschäftigung mit Dämonischem und mit Mesmerismus - Doppelgänger und unkontrolliertes Eigenleben der Triebe

4. UNHEIMLICHE IDENTITÄTSVERSTÜMMELUNGEN

Erotische Entgrenzung und Automatenmensch in Arnims "Melück Maria Blainville" • Weggezaubertes Herz, weggetauschter Schatten, verschenktes Spiegelbild: Identität ohne 'solide' Konsistenz in Arnims "Melück Maria Blainville", Chamissos "Schlemihl", Hoffmanns "Verlornem Spiegelbilde"

5. Chaotische Selbsthilfe

Das Überich als Doppelgänger in Poes "William Wilson" • Besserungsbemühung und Ichspaltung in Raimunds "Verschwender" und "Alpenkönig und Menschenfeind"

6. DOPPELGÄNGERSPALTUNG UND MODERNE LEBENSWELT

Verstädterung des Doppelgängers in Dostojewskijs "Doppelgänger" • Konkurrenzwirtschaft und Doppelgängertum in Brentanos "Mehreren Wehmüllern" - Rationelle Gesellschaft und Identitätsverstümmelung in Görres'/Brentanos "Bogs der Uhrmacher" • Liberalistische Arbeitswelt und existentielle Schwindelgefühle in Dostojewskijs "Doppelgänger" • Viktorianische Großstadt und Doppel-Ich in Stevensons "Dr. Jekyll and Mr. Hyde"

1. Das ICh als PluRal

Stevensons Doppelwesen Jekyll/Hyde und die Verwerfung der Einheit des Ich bei Nietzsche und Mach • Multiple Persönlichkeit als Thema der Psychiatrie der 80er Jahre 
- "The terrible pleasures of a double life" in Bourgets "Disciple" und in Wildes "Dorian Gray"

2. GANZHEIT JENSEITS VOM ICH

Der Doppelgänger als Teufel in Dostojewskijs "Brüdern Karamasow" • Das Ich als Mephistopheles in Werfels "Spiegelmenschen" • Doppelgänger, Wiederholungszwang und Sehnsucht nach dem Differenzlosen in Kaisers "Koralle" und "Zweimal Oliver"

\section{DOPPELGÄNGERBEGEGNUNGEN UND AUSWEITUNG VON}

\section{SELBSTERFAHRUNG}

Schismatische Persönlichkeit und okkultistische Individuation in Meyrinks "Golem" • Das 'Fest der Dissoziation' in Hesses "Steppenwolf" • Doppelgänger als Effekt moderner Stilprinzipien in Golls "Methusalem"

1. ICH-ERZÄHLUNG ALS DOPPELGÄNGERSPIEL Ich-Erzähler auf Suche nach Protagonisten: Frischs "Gantenbein" • Entglittenes Ichpronomen und Doppelgängereffekte im "Gantenbein" und in C.Wolfs "Kindheitsmustern"

Geschmack von Unwirklichkeit bei Borges • Kon-fusionen in Robbe-Grillets "Djinn" • Hilbigs entwirklichte Helden

\section{Bibliographie 274}

